Check for updates

Cite this: RSC Adv., 2019, 9, 35588

\title{
Improved nanocomposite of montmorillonite and hydroxyapatite for defluoridation of water
}

\author{
M. Shanika Fernando, ${ }^{a}$ A. K. D. V. K. Wimalasiri, ${ }^{a}$ S. P. Ratnayake, ${ }^{b}$ \\ J. M. A. R. B. Jayasinghe, (D) ${ }^{a}$ Gareth R. William, (D) ${ }^{c}$ D. P. Dissanayake, ${ }^{a}$ K. M. Nalin de \\ Silva (D) and Rohini M. de Silva (D) *a
}

A novel hydroxyapatite montmorillonite (HAP-MMT) nanocomposite system was synthesized using a simple wet chemical in situ precipitation method. Neat nano hydroxyapatite (HAP) was also synthesized for comparison. The characterization of the materials was carried out using Fourier Transform Infrared Spectroscopy (FT-IR), Scanning Electron Microscopy (SEM), X-ray diffraction (XRD) and BrunauerEmmett-Teller (BET) isotherms to study the functional groups, morphology, crystallinity and the surface area respectively. Batch adsorption studies and kinetic studies on fluoride adsorption were conducted for the HAP-MMT system and for neat HAP. The effect of parameters such as contact time, $\mathrm{pH}$, initial concentration, temperature, and thermodynamic parameters and the effect of coexisting ions on fluoride adsorption by HAP-MMT were studied. Results of the isotherm experiments were fitted to four adsorption isotherm models namely Langmuir, Freundlich, Temkin and Dubinin Radushkevich. Fluoride adsorption over HAP-MMT fitted to the Freundlich adsorption isotherm model and showed more than two-fold improved adsorption capacity $\left(16.7 \mathrm{mg} \mathrm{g}^{-1}\right)$ compared to neat HAP. The best-fitting kinetic model for both adsorbents was found to be pseudo second order. Calculated thermodynamic parameters indicated that the fluoride adsorption by HAP-MMT is more favorable compared to that on HAP within the temperature range of $27{ }^{\circ} \mathrm{C}-60{ }^{\circ} \mathrm{C}$. Improved fluoride adsorption by HAP-MMT is attributed to the exfoliated nature of HAP-MMT. Gravity filtration studies carried out using a $1.5 \mathrm{ppm}$ fluoride solution, which is closer to the ground water fluoride concentrations of Chronic Kidney Disease of unknown etiology (CKDu) affected areas in Sri Lanka, resulted in a $1600 \mathrm{ml} \mathrm{g}^{-1}$ break through volume indicating the potential of HAP-MMT to be used in real applications.

\author{
Received 26th May 2019 \\ Accepted 23rd October 2019 \\ DOI: $10.1039 / c 9 r a 03981 c$ \\ rsc.li/rsc-advances
}

\section{Introduction}

Fluoride is a naturally found element in water bodies and fluoride intake within the permissible levels is beneficial as an essential nutrient for the prevention of dental caries and making strong bones. ${ }^{1}$ However, long-term consumption of water with fluorides at elevated levels (according to WHO above 1.5-2.0 ppm) can cause adverse health effects. ${ }^{2}$ Dental and skeletal fluorosis is considered to be the most noticeable health hazard and is common in many parts of the world, including India and Sri Lanka. ${ }^{3}$ In addition, it has also been identified that this can cause different types of chronic diseases that can affect renal, gastrointestinal and immunological systems. ${ }^{4}$ Recently,

${ }^{a}$ Centre for Advanced Materials and Devices (CAMD), Department of Chemistry, University of Colombo, Colombo 03, Sri Lanka.E-mail: rohini@chem.cmb.ac.lk

${ }^{b}$ Sri Lanka Institute of Nanotechnology (SLINTEC), Nanotechnology and Science Park, Pitipana, Homagama, Sri Lanka

${ }^{c}$ UCL School of Pharmacy, University College London, 29-39 Brunswick Square, London, WCIN $1 A X, U K$

$\dagger$ Electronic supplementary information (ESI) available. See DOI: 10.1039/c9ra03981c fluoride has been identified as one of the main causative agents for chronic kidney disease with unknown etiology (CKDu), in Sri Lanka, which is considered as one of the alarming health issues in the country. ${ }^{5,6}$ Among the existing water defluorination methods, adsorption has been identified as one of the best methods and has been extensively studied and reviewed..$^{7-13}$ In comparison to the different types of bulk materials which have been studied for fluoride adsorption, metal oxides and hydroxides of titanium, ${ }^{5,14}$ iron, ${ }^{15,16}$ lanthanum $^{17}$ and aluminium $^{\mathbf{1 8}}$ are identified as the most frequently studied materials with higher adsorption capacities. Further, different types of nanomaterials including other metal oxides ${ }^{11,19-22}$ metal oxide hybrids ${ }^{23,24}$ and hydroxides, ${ }^{22,25-28}$ and carbon nanotubes, ${ }^{29-31}$ have also been tested on removing fluoride ions. However, as indicated by Stanic et al. ${ }^{32}$ these adsorbents have only a limited applicability due to their high cost and toxicity. Therefore, it is of utmost importance to find efficient and costeffective alternative methods that can remove excessive levels of fluorides from water. Nano hydroxyapatite is a nontoxic material which has been extensively used in biomedical applications and HAP based nanocomposites have been identified as 
promising materials in water purification. ${ }^{30,33-35}$ Several researchers have studied the fluoride adsorption properties of nano hydroxyapatite which are synthesized by different methods and many of these resulted a comparatively low adsorption capacity with a long contact times. ${ }^{36-39}$ In addition, the inherent affinity of cations such as $\mathrm{Al}$ towards fluoride has led many scientists to explore clay minerals as sorbents to water de-fluorination. In this regard, different type of clay minerals such as kaolinite, ${ }^{40}$ montmorillonite, ${ }^{41,42}$ bentonite, ${ }^{43}$ pyrophyllite $^{44}$ and meixnerite ${ }^{45,46}$ have been considered. Of these, clay minerals, montmorillonite (MMT) is a well-known smectite nano clay which is used in biomedical applications as well as to remove metal ions. ${ }^{47,48}$ However, fluoride adsorption studies carried out with MMT has resulted very low fluoride adsorption capacities with long contact hours at neutral $\mathrm{pH}^{4{ }^{41}}$ Therefore, in our study, incorporation of nano HAP with MMT nano clay was thought to improve adsorption properties of fluorides, as it may facilitate the creation of more adsorption sites to interact. Also the combination of nanohydroxyapatite and MMT was preferred as they are comparatively cheap materials which can be formed into a composite using a simple and cost effective one pot synthesis method, without maintaining high temperatures.

\section{Materials and method}

\subsection{Materials}

All the chemicals used were analytical grade and used without further purification. Ammonium hydroxide $\left(\mathrm{NH}_{4} \mathrm{OH}\right.$ solution, $25 \%$, Sigma Aldrich), calcium nitrate tetrahydrate $\left(\mathrm{Ca}\left(\mathrm{NO}_{3}\right)_{2}^{-}\right.$ $\cdot 4 \mathrm{H}_{2} \mathrm{O}, 98 \%$ Sigma Aldrich), di-ammonium hydrogen orthophosphate $\left(\left(\mathrm{NH}_{4}\right)_{2} \mathrm{HPO}_{4}, 98 \%\right.$ Sigma Aldrich) were used to synthesis neat HAP. Montmorillonite (Sigma Aldrich) was used to synthesis HAP-MMT nanocomposites and sodium fluoride, 99.5\% (Merck) was used to prepare the fluoride stock solutions.

\subsection{Synthesis of hydroxyapatite nanoparticles}

Nano hydroxyapatite was synthesized according to the modified method reported earlier by us. ${ }^{7}$ In brief $\left(\mathrm{NH}_{4}\right)_{2} \mathrm{HPO}_{4}$ was added dropwise into $\mathrm{Ca}\left(\mathrm{NO}_{3}\right)_{2} \cdot 4 \mathrm{H}_{2} \mathrm{O}$ solution maintaining the $\mathrm{Ca} / \mathrm{P}$ ratio to 1.67 at $60{ }^{\circ} \mathrm{C}$ with vigorous stirring. The $\mathrm{pH}$ was maintained at 10 with dropwise addition of $\mathrm{NH}_{4} \mathrm{OH}(5 \mathrm{M})$ and then the mixture was vigorously stirred at its boiling point for about $3 \mathrm{~h}$. The mixture was aged for 24 hours at room temperature and the HAP precipitate was washed until its $\mathrm{pH}$ became neutral. The product was separated by centrifugation. The resultant solid was oven dried at $80{ }^{\circ} \mathrm{C}$ until a constant weight was obtained.

\subsection{Synthesis of HAP-MMT nanocomposites}

$5 \%(\mathrm{w} / \mathrm{v})$ MMT was mixed with distilled water and kept overnight to swell and facilitate better exfoliation. Then the MMT slurry was stirred vigorously for 1 hour and in situ precipitation of HAP was carried out following the same procedure explained above. Samples where the HAP : MMT ratio of the final product to be $2: 1,1: 1,1: 2$ and $1: 4$ were synthesized in this manner.
The resulted product was washed and separated by centrifugation. Then it was oven dried at $80^{\circ} \mathrm{C}$ for 3 hours. The nanocomposite prepared with HAP : MMT ratio $1: 1$ was identified as the best ratio as it gave the best defluorination capacity with a favourable texture (Refer S1 and S2 in the ESI $\dagger$ ).

\subsection{Characterization of the materials}

Scanning Electron Microscopy (SEM) images of both HAP nanoparticles and HAP-MMT nanocomposite were obtained using a Hitachi SU6600 Scanning Electron Microscope (SEM) to analyses the surface characteristics of the adsorbents. Fourier Transform Infrared Spectrometer (FT-IR)-AVATAR-320 (Thermo Nicolet) was used to analyse the functional groups and the molecular interactions of the samples in the wave number range between $500 \mathrm{~cm}^{-1}$ and $4000 \mathrm{~cm}^{-1}$. Samples were prepared in the form of pellets using $\mathrm{KBr}$, maintaining the $\mathrm{KBr}$ : sample mass ratio at $1: 10$. X-ray diffraction analysis of the synthesized HAP nanoparticles and HAP-MMT nanocomposite was performed using a Bruker D8 Focus X-ray powder diffractometer using CuK $\alpha$ radiation $(=0.154 \mathrm{~nm})$ over the $2 \theta$ range of $3^{\circ}-60^{\circ}$, with a step size of $0.02^{\circ}$ and a step time of $1 \mathrm{~s}$. The Brunauer-Emmett-Teller (BET) surface area measurements were carried out using a Beckman coulter sorption analyser.

\subsection{Fluoride adsorption studies}

A stock solution of $100 \mathrm{ppm}$ fluoride was prepared using sodium fluoride in a polypropylene container. Batch adsorption studies were carried out in polypropylene containers $(60 \mathrm{ml})$ with constant agitation at $200 \mathrm{rpm}$ with the aid of an orbital shaker.

The adsorption capacities were calculated according to eqn (1), where $Q_{\mathrm{e}}$ is the adsorption capacity $\left(\mathrm{mg} \mathrm{L}^{-1}\right), C_{0}$ is the initial concentration $\left(\mathrm{mg} \mathrm{L}^{-1}\right), C_{t}$ is the concentration after contacting time ( $\mathrm{mg} \mathrm{L}^{-1}$ ), $V$ is the volume (L) of aqueous solution and $m$ is the mass of the adsorbent $(\mathrm{g})$.

$$
Q_{\mathrm{e}}=\left(C_{0}-C_{t}\right) V / m \times 1000
$$

2.5.1. Analysis for fluorides. Fluoride concentrations of solutions were analysed using a fluoride ion selective electrode. Each sample $(8.0 \mathrm{ml})$ was mixed with TISAB solution $(8.0 \mathrm{ml})$ before measuring the electrode potential $(\mathrm{mV})$ of the fluoride selective electrode (details are given in S2 in the ESI $\dagger$ ).

2.5.2. Effect of time. The effect of time on the adsorption capacity was investigated at different time periods (1-240 min) for HAP and HAP-MMT, using $20.0 \mathrm{ml}$ of $30 \mathrm{ppm}$ fluoride solution and $0.02 \mathrm{~g}$ of adsorbent at room temperature $(27 \pm 1$ $\left.{ }^{\circ} \mathrm{C}\right)$ and at the $\mathrm{pH}$ of drinking water $(6.5 \pm 0.2)$.

2.5.3. Batch adsorption isotherm studies. Data for the adsorption isotherms were obtained in the concentration range of 1-30 ppm of fluoride for HAP-MMT and HAP with constant stirring at $200 \mathrm{rpm}$, for periods of 60 and 240 minutes, respectively. 
Data obtained were analysed using four adsorption isotherm models (Langmuir, Freundlich, Temkin and Dubinin Radushkevich) in order to identify the best fitting isotherm model. The linearized form of the Langmuir adsorption isotherm that is used to describe monolayer adsorption is given in eqn (2).

$$
C_{\mathrm{e}} / Q_{\mathrm{e}}=1 / Q_{\mathrm{L}} k_{\mathrm{L}}+C_{\mathrm{e}} / Q_{\mathrm{L}}
$$

where, $C_{\mathrm{e}}, Q_{\mathrm{e}}, K_{\mathrm{L}}, Q_{\mathrm{L}}$ are the concentration of the adsorbate at the equilibrium $\left(\mathrm{mg} \mathrm{L}^{-1}\right)$, the adsorption capacity $\left(\mathrm{mg} \mathrm{g}^{-1}\right)$, Langmuir isotherm constant $\left(\mathrm{L} \mathrm{mg}^{-1}\right)$ and the maximum monolayer adsorption capacity $\left(\mathrm{mg} \mathrm{g}^{-1}\right)$ respectively.

The linear forms of the Freundlich adsorption isotherm is illustrated in eqn (3) and the Freundlich adsorption isotherm is plotted against $\log Q_{\mathrm{e}} v s$. $\log C_{\mathrm{e}}$, where, $Q_{\mathrm{e}}$ and $C_{\mathrm{e}}$ are adsorption capacity $\left(\mathrm{mg} \mathrm{g}^{-1}\right)$ and the concentration $\left(\mathrm{mg} \mathrm{L}^{-1}\right)$ at the equilibrium while $K_{\mathrm{f}}$, and $n$ represent Freundlich adsorption isotherm constants.

$$
\log Q_{\mathrm{e}}=\log K_{\mathrm{f}}+1 / n \log C_{\mathrm{e}}
$$

Temkin isotherm model which takes in to account the induced heterogeneity, ${ }^{49}$ was also applied in linear form as given in the eqn (4), where $q_{\mathrm{e}}$ is the adsorption capacity, $C_{\mathrm{e}}$ is the concentration at the equilibrium, where, $k_{\mathrm{t}}$ is the Temkin isotherm binding constant, and $B_{\mathrm{t}}$ is the constant related to the heat of sorption.

$$
q_{\mathrm{e}}=B_{\mathrm{t}}\left(\ln k_{\mathrm{t}}\right)+B_{\mathrm{t}}\left(\ln C_{\mathrm{e}}\right)
$$

The results of the adsorption data were also tested with the Dubinin-Radushkevich model which is given in the eqn (5), where $q_{\mathrm{e}}$ and $Q_{\mathrm{m}}$ are the adsorption capacity at the equilibrium and theoretical adsorption capacity in $\mathrm{mg} \mathrm{g}^{-1}$ respectively. $K_{\mathrm{DR}}$ is the activity coefficient related to the free energy of adsorption and $\varepsilon$ is known as Polanyi potential and $\varepsilon_{2}$ is calculated according to eqn (6).

$$
\begin{gathered}
\ln q_{\mathrm{e}}=\ln \left(Q_{\mathrm{m}}\right)-K_{\mathrm{DR}} \varepsilon^{2} \\
\varepsilon_{2}=R T \ln \left(1+\left(1 / C_{\mathrm{e}}\right)\right.
\end{gathered}
$$

The mean of adsorption energy, $E$ was calculated using the eqn 7.

$$
E=2 K_{\mathrm{DR}}^{1 / 2}
$$

2.5.4. Kinetic studies. Kinetics for the defluorination by HAP and HAP-MMT was studied using a $30 \mathrm{ppm}$ initial fluoride concentration. Results were fitted to pseudo first order, pseudo second order and intraparticle diffusion kinetic models. The linear form of the first order kinetics model can be expressed as in the general equation given in eqn (8) where $q_{\mathrm{e}}$ and $q_{t}$ are the adsorption capacity $\left(\mathrm{mg} \mathrm{g}^{-1}\right)$ at the equilibrium and time $t$ and $k_{1}$ is the pseudo first order adsorption rate constant $\left(\mathrm{min}^{-1}\right)$.

$$
\log \left(q_{\mathrm{e}}-q_{t}\right)=\log \left(q_{\mathrm{e}}\right)-k_{1} t / 2.303
$$

The pseudo second order kinetic model is given in the eqn (9), where $k_{2}$ is the pseudo second order rate constant.

$$
t / q=1 / k_{2} q_{\mathrm{e}}^{2}+1 / q_{\mathrm{e}} t
$$

Intraparticle diffusion model is described in the eqn (10), where $q_{t}$ is the adsorption capacity $\left(\mathrm{mg} \mathrm{g}^{-1}\right) k_{\mathrm{p}}$ is the intraparticle diffusion rate constant $\left(\mathrm{mg} \mathrm{g}^{-1} \mathrm{~min}^{-1 / 2} \mathrm{~g}^{-1}\right)$ and $C$ is the intercept, ${ }^{50}$

$$
q_{t}=k_{\mathrm{p}} t^{1 / 2}+C
$$

2.5.5. The effect of $\mathbf{p H}$ on fluoride ion adsorption. In order to identify the improved adsorption properties of the HAP-MMT nanocomposite at the drinking water $\mathrm{pH}$ levels, the adsorption studies were carried out separately for HAP, MMT, HAP-MMT composites and also for a physical mixture of HAP, MMT with $1: 1$ ratio at different $\mathrm{pH}$ levels. ${ }^{2-11}$ Experiments were conducted for $20 \mathrm{ml}$ of $10 \mathrm{ppm}$ fluoride solutions and the dose of the adsorbent at $0.04 \mathrm{~g}$.

2.5.6. The effect of temperature and thermodynamic parameters. The adsorption studies were conducted at different temperatures $\left(27{ }^{\circ} \mathrm{C}, 35^{\circ} \mathrm{C}, 40{ }^{\circ} \mathrm{C}, 50{ }^{\circ} \mathrm{C}\right.$ and $\left.60{ }^{\circ} \mathrm{C}\right)$ for the removal of fluoride by both HAP and HAP-MMT separately by maintaining the identical reaction conditions such as initial fluoride concentration (15 ppm), adsorbent dosage (0.02 g), shaking time and the speed. Thermodynamic parameters, Gibbs free energy change $\left(\Delta G^{\circ} \mathrm{kJ} \mathrm{mol}^{-1}\right)$, standard entropy change $\left(\Delta S^{\circ} \mathrm{kJ}^{-1}\right.$ mol K $\left.\mathrm{K}^{-1}\right)$ and standard enthalpy change $\left(\Delta H^{\circ} \mathrm{kJ} \mathrm{mol}^{-1}\right)$ were calculated by the following equations (eqn (11) and (12)) where $R\left(\mathrm{~J} \mathrm{~mol}^{-1} \mathrm{~K}^{-1}\right)$ is the universal gas constant $T$ is the temperature in kelvin. $K_{\mathrm{d}}$ is the distribution coefficient of the solute and $K_{\mathrm{d}}$ was calculated using $C_{\mathrm{a}} / C_{\mathrm{e}}$ where $C_{\mathrm{a}}$ is the adsorbate concentration on the adsorbent at the equilibrium and $C_{\mathrm{e}}$ is the concentration of the adsorbate in the solution at the equilibrium. ${ }^{51}$

$$
\begin{gathered}
\Delta G^{\circ}=R T \ln K_{\mathrm{d}} \\
\ln K_{\mathrm{d}}=\Delta S^{\circ} / R-\Delta H^{\circ} / R T
\end{gathered}
$$

\subsection{Effect of co-existing anions}

In order to investigate the effect of co-existing ions on fluoride adsorption by both HAP and HAP-MMT adsorbents, separate adsorption studies were conducted using $10.0 \mathrm{ml}$ of $10 \mathrm{ppm}$ fluoride solutions. Study was conducted at two different concentrations (20 ppm and $200 \mathrm{ppm}$ ) of the ions namely, $\mathrm{NO}_{3}{ }^{-}, \mathrm{NO}_{2}{ }^{-}, \mathrm{SO}_{4}{ }^{2-}, \mathrm{HCO}_{3}{ }^{-}, \mathrm{Cl}^{-}$and $\mathrm{OH}^{-}$.

\subsection{Gravity filtration}

Gravity filtration studies were carried out using $1.5 \mathrm{ppm}$ fluoride solution. The solution was passed at a rate of $0.33 \mathrm{ml} \mathrm{s}^{-1}$ through a column with a diameter of $1 \mathrm{~cm}$ across a filter bed prepared with HAP-MMT (0.05 g) deposited evenly on $0.05 \mathrm{~g}$ of 
a cotton bed. The break through capacity was calculated using the volume of fluoride solution that could be passed through the column before the fluoride concentration of the filtrate exceeds $0.5 \mathrm{ppm}$.

\subsection{Reusability test}

Fluoride adsorbed HAP-MMT nanocomposite was used to test the reusability of the nanocomposite. Fluoride adsorbed HAPMMT was filtered and separated from the solution and dipped in $1 \mathrm{M}, \mathrm{NaOH}$ overnight. Then it was washed well with double distilled water until the $\mathrm{pH}$ become neutral and oven dried. The samples were subjected for 3 cycles of fluoride adsorption.

\section{Results and discussion}

\subsection{Characterization of the materials}

Fig. S3 in ESI $\dagger$ illustrates the FTIR spectra of neat HAP, neat MMT and HAP-MMT respectively. The characteristic sharp peak at $3570 \mathrm{~cm}^{-1}$ (ref. 7) due to the $\mathrm{OH}$ stretching of HAP is clearly visible in the IR spectrum of HAP while neat MMT show a prominent peak at $3640 \mathrm{~cm}^{-1}$ due to $\mathrm{OH}$ stretching. ${ }^{52}$ However, in HAP-MMT composite, there is a broad band in the region of $3700-3000 \mathrm{~cm}^{-1}$. This can be attributed to the overlapping of the two peaks resulting from both neat HAP and MMT. The band at $1410 \mathrm{~cm}^{-1}$ in HAP-MMT composite can be credited to the duplex peak of HAP around $1400 \mathrm{~cm}^{-1}$ due to carbonate stretching. This indicates the successful incorporation of HAP in the composites. The presence of small peaks around $914-840 \mathrm{~cm}^{-1}$ region in both neat MMT and HAP-MMT composites and these peaks are due to $\mathrm{Al}$ and $\mathrm{Mg}$ ion interactions with $\mathrm{OH}-\left(\mathrm{Al}_{2} \mathrm{OH}\right.$ near $920 \mathrm{~cm}^{-1}, \mathrm{Al}-\mathrm{OH}$ around $890 \mathrm{~cm}^{-1}$, and $\mathrm{OH}-$ in $\mathrm{Mg}-\mathrm{OH}$ near $\left.840 \mathrm{~cm}^{-1}\right) \cdot{ }^{47-49} \mathrm{In}$ addition, the band at $1035 \mathrm{~cm}^{-1}$ in neat HAP and HAP-MMT composites is due to phosphate stretching as reported in literature. This also confirms the successful incorporation of HAP into MMT. ${ }^{53,54}$ The Scanning Electron Microscopy (SEM) images of MMT, HAPMMT and fluoride adsorbed HAP-MMT (HAP-MMT-F) are shown in Fig. S4. $\dagger$ The SEM of neat HAP indicates that they are in the nanoscale similar to our previous work ${ }^{7}$ with $80 \mathrm{~nm}$ of length and $30 \mathrm{~nm}$ of width and show a rod like morphology. The SEM image of neat MMT shows flat planes with continuous arrangement. In comparison, HAP-MMT composite shows expanded, disordered flakes with considerable number of pores with depositions of HAP and a large surface area. This exfoliated nature of HAP-MMT composite indicated that there is a higher tendency for exposing more cationic sites for $\mathrm{F}^{-}$to get bonded with. Higher surface area was further confirmed with BET data as discussed below. According to Fig. S4(d), $\dagger$ an extensive exfoliation of HAP-MMT composite can be seen after adsorption of $\mathrm{F}^{-}$ions. This image further revealed, peeled out plates like morphology of HAP-MMT composite indicating further expansion of the layers due to adsorption of $\mathrm{F}^{-}$ions at hydroxide sites of the intercalated space, as shown in the mechanism (Fig. 6). This is further supported by the XRD pattern observed for HAPMMT composite (Fig. 1) which shows amorphous nature of MMT after $\mathrm{F}^{-}$being adsorbed.

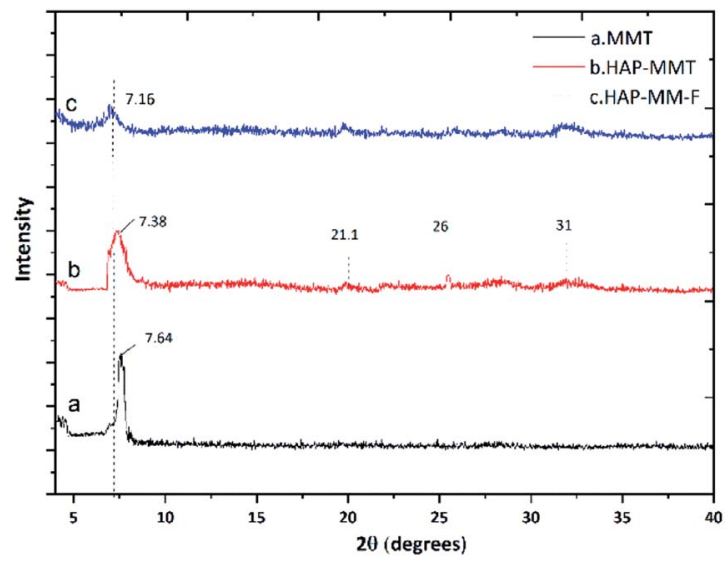

Fig. 1 XRD of MMT, HAP-MMT and fluoride adsorbed HAP-MMT (HAP-MMT-F).

As shown in Fig. 1, the X-ray diffraction pattern of neat MMT, HAP-MMT and HAP-MMT-F show prominent peaks at $2 \theta=7.64$, 7.38 and 7.16 respectively. In addition, two peaks corresponding to HAP at $2 \theta=21^{\circ}, 26^{\circ}$ and $34^{\circ}$ can also be seen with lower intensity in HAP-MMT composite and this indicates a successful synthesis of HAP. ${ }^{55}$ The $d$-spacing which were calculated according to the Bragg's equation $(n \lambda=2 d \sin \theta)$ corresponding to the prominent peaks resulted for MMT, HAP-MMT and HAPMMT-F were $11.38 \mathrm{~A}^{\circ}, 11.61 \mathrm{~A}^{\circ}$ and $12.32 \mathrm{~A}^{\circ}$ respectively. The enhancement of the $d$ spacing in the formation of HAP-MMT indicated the intercalation of HAP nanoparticles in to the layers of MMT. ${ }^{56}$ Expansion of layers to provide more spaces is also evident from BET isotherm analysis, where it was found to increase from 46.4 for neat HAP to $78.98 \mathrm{~m}^{2} \mathrm{~g}^{-1}$ for HAP-MMT (resulted plots are given in Fig. S5 in the ESI $\dagger$ ). Further enhancement of the $d$ spacing in fluoride adsorbed HAP-MMT-F is in support of exfoliation of the structure in the process of fluoride adsorption.

\subsection{Adsorption studies}

3.2.1. Effect of contact time. The effect of contact time on the adsorption of $\mathrm{F}$ - ions for three composites were carried out using initial $\mathrm{F}^{-}$concentration of $30 \mathrm{ppm}$ for 2 hours. The

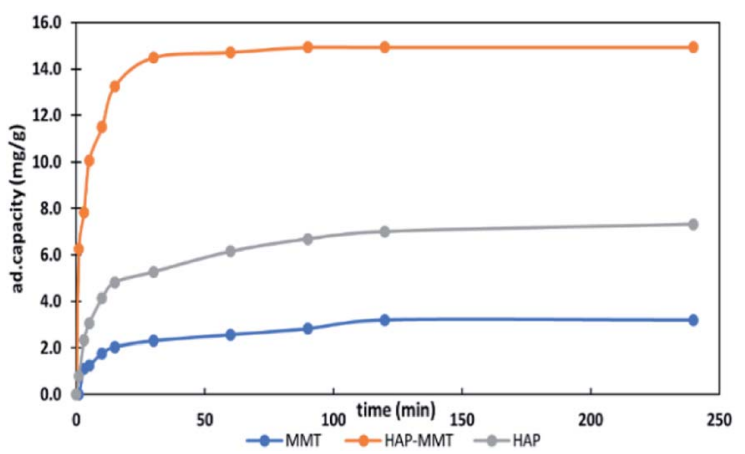

Fig. 2 Effect of contact time on the adsorption capacity of fluoride ions. 

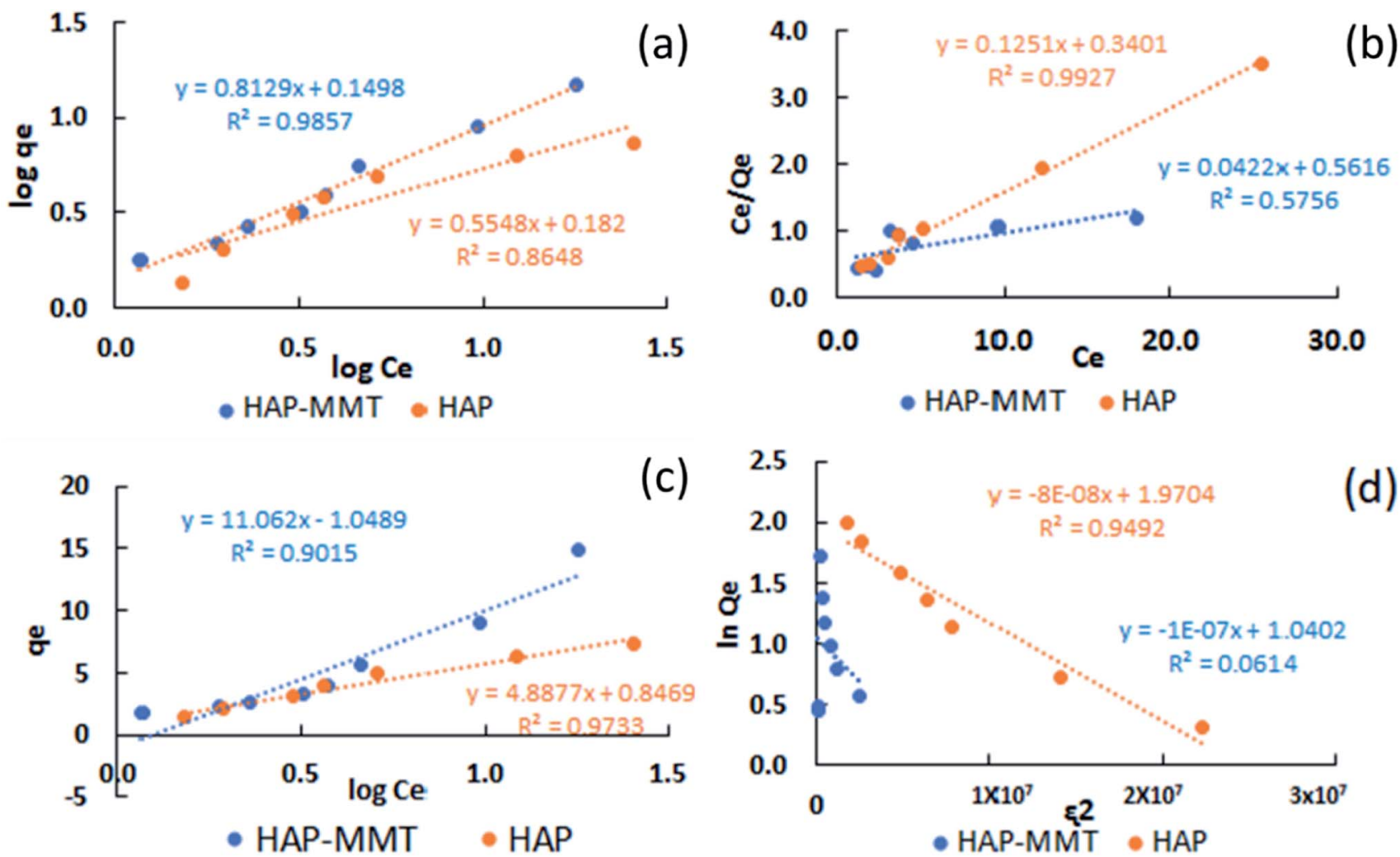

(d)

Fig. 3 (a) Langmuir, (b) Freundlich, (c) Temkin, (d) Dubinin Radushkevich adsorption isotherms for HAP-MMT and HAP.

graphical representation of the results is shown in Fig. 2. Accordingly, HAP-MMT shows the fastest kinetics and improved adsorption properties than that of neat HAP. Also, the results indicate that HAP-MMT reaches more than $50 \%$ of its maximum adsorption capacity within the first 5 minutes and reaches the maximum level within 30 minutes. Therefore, HAPMMT was identified as the best system and only that system was subjected to batch adsorption studies and kinetic studies along with neat HAP for comparison.

\subsection{Adsorption isotherms for fluorides}

Adsorption isotherms are important to study the properties and the behaviour of the process of adsorption. Data obtained for the batch adsorption studies were fitted to four isotherm models (Freundlich, Langmuir, Temkin and Dubinin Radushkevich) as explained in the experimental section.

Fig. 3 illustrates the resulted plots by all four isotherm models. Adsorption isotherm constants were calculated for each model and resulted values are summarized in Table 1 with

Table 1 Langmuir, Freundlich, Temkin and Dubinin Radushkevich isotherm constants for fluoride adsorption by neat HAP and HAP-MMT

\begin{tabular}{|c|c|c|c|}
\hline & & HAP-MMT & HAP \\
\hline Experimental data & $q_{\mathrm{e}}\left(\mathrm{mg} \mathrm{g}^{-1}\right)$ & 14.90 & 7.32 \\
\hline \multirow[t]{2}{*}{ Langmuir isotherm constants } & $Q_{\mathrm{L}}\left(\mathrm{mg} \mathrm{g}^{-1}\right)$ & 23.70 & 6.71 \\
\hline & $R^{2}$ & 0.576 & 1.00 \\
\hline \multirow{2}{*}{ Freundlich isotherm constants } & $n$ & 1.230 & 1.98 \\
\hline & $Q_{\mathrm{e}}\left(\mathrm{mg} \mathrm{g}^{-1}\right)$ & 16.71 & 6.98 \\
\hline \multirow[t]{3}{*}{ Temkin isotherm constants } & $K_{\mathrm{t}}\left(\mathrm{L} \mathrm{g}^{-1}\right)$ & 0.910 & 1.327 \\
\hline & $B_{\mathrm{t}} \times 10^{3}$ & 11.062 & 4.157 \\
\hline & $R^{2}$ & 0.902 & 0.904 \\
\hline \multirow{3}{*}{$\begin{array}{l}\text { Dubinin Rarushkevish isotherm } \\
\text { constant }\end{array}$} & $K_{\mathrm{DR}}\left(\mathrm{mol}^{2} \mathrm{~J}^{-2}\right)$ & $1 \times 10^{-7}$ & $8 \times 10^{-8}$ \\
\hline & $Q_{\mathrm{m}}\left(\mathrm{mg} \mathrm{g}^{-1}\right)$ & 2.829 & 6.810 \\
\hline & $E\left(\mathrm{~kJ} \mathrm{~mol}^{-1}\right)$ & 1.414 & 0.000 \\
\hline
\end{tabular}


Table 2 Kinetic constants for HAP-MMT and HAP on fluoride adsorption

\begin{tabular}{llll}
\hline & & HAP-MMT & HAP \\
\hline Experimental data & $Q_{\mathrm{e}}(\mathrm{exp}) \mathrm{mg} \mathrm{g}^{-1}$ & 14.92 & 7.32 \\
Pseudo first order & $k_{1}(\mathrm{cal})\left(\mathrm{mg} \mathrm{g}^{-1}\right)$ & -0.215 & -0.208 \\
& $Q_{\mathrm{e}}(27.673$ & 21.409 \\
& $R^{2}$ & 0.8817 & 0.7922 \\
Pseudo second order & $Q_{\mathrm{e}}(\mathrm{cal}) \mathrm{mg} \mathrm{g}^{-1}$ & 15.08 & 7.51 \\
& $k_{2}\left(\mathrm{gmg}^{-1} \mathrm{~S}\right)$ & 0.014 & 0.020 \\
& $R^{2}$ & 0.999 & 0.997 \\
Intraparticle diffusion & $K_{\mathrm{p}}\left(\mathrm{mg} \mathrm{g}^{-1} \mathrm{~min}^{-1 / 2}\right)$ & 2.5042 & 1.5546 \\
& $C$ & 0.322 & 0.367 \\
& $R^{2}$ & 0.7465 & 0.6560 \\
\hline
\end{tabular}

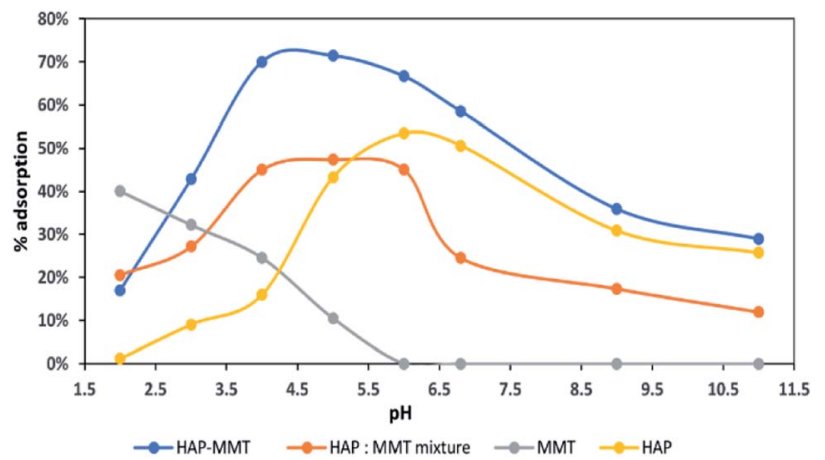

Fig. 4 The effect of $\mathrm{pH}$ on adsorption capacity of $\mathrm{F}^{-}$and adsorption percentage.

their correlation coefficients $\left(R^{2}\right)$. Freundlich model was found to be the best model $\left(R^{2}=0.986\right)$ that describes the fluoride adsorption by HAP-MMT. This indicates that the fluoride removal by HAP-MMT is characterized with a multilayer adsorption which is mostly shown by the systems with heterogenous surfaces. ${ }^{30,35}$ The maximum adsorption capacity calculated for HAP-MMT, by the best fit Freundlich model was $16.7 \mathrm{mg} \mathrm{g}^{-1}$, while the experimental adsorption capacity was found to be $14.9 \mathrm{mg} \mathrm{g}^{-1}$. This value can be considered as a relatively high adsorption capacity when compared with the adsorption capacities obtained for other HAP based nanocomposites containing biocompatible materials. ${ }^{52-54}$ Also, the $n$ value calculated for HAP-MMT by the Freundlich model was 1.23 and this indicates that the process of adsorption is favourable as the resulted value is below 10. The other models could be fitted in the order of Temkin $\left(R^{2}=0.902\right)$, Langmuir $\left(R^{2}=0.576\right)$ and $\mathrm{D}-\mathrm{R}$ isotherm $\left(R^{2}=0.0614\right)$. Temkin model can be used to describe a system with induced heterogeneity and $\mathrm{D}-\mathrm{R}$ model is used to explain an adsorption mechanism of Gaussian energy distribution on a heterogeneous surface. In comparison fluoride adsorption on neat HAP was fitted well with the Langmuir adsorption isotherm $\left(R^{2}=0.993\right)$ and resulted a $6.71 \mathrm{mg} \mathrm{g}^{-1}$.

\subsection{Adsorption kinetics}

In addition to the adsorption isotherms, kinetic data were obtained for both neat HAP and HAP-MMT at $30 \mathrm{ppm}$ initial concentration of fluoride to evaluate the kinetic model and the kinetic constantans. Kinetic data were fitted in to pseudo-firstorder, pseudo-second-order and intraparticle diffusion models and the resulted plots are shown in the Fig. S6 in ESI. $\dagger$ The kinetic constants of the three models $\left(k_{1}, k_{2}, k_{\mathrm{p}}\right)$, the adsorption capacity calculated by the kinetic models and the experimentally resulted adsorption capacities $\left(Q_{\mathrm{e}}\right.$ (cal.) and $\left.Q_{\mathrm{e}}(\exp ).\right)$ and the correlation coefficients $\left(R^{2}\right)$ are calculated and tabulated in Table 2. Maximum monolayer adsorption capacity while the other isotherm models were fitted in the order of D-R $\left(R^{2}=\right.$ $0.9614)$, Temkin $\left(R^{2}=0.904\right)$ and Freundlich $\left(R^{2}=0.805\right)$.

According to the results, pseudo second order kinetic model show comparatively higher $R^{2}$ values for both HAP-MMT and HAP. In addition, the kinetics data show that the values of $q_{\mathrm{e}}$, $q_{\text {(cal.) }}$ by pseudo second order kinetic model are closer to the experimental $q_{\mathrm{e}}$ value at both the concentrations (Table 2). Therefore, it can be predicted that the adsorption of fluorides on both nano HAP and HAP-MMT follow pseudo second order kinetic model.

\subsection{Effect of $\mathbf{p H}$}

The effect of $\mathrm{pH}$ is considered as one of the important parameters that can affect the process of adsorption, as changing $\mathrm{pH}$ can alter the surface charges of the adsorbents. The effect of $\mathrm{pH}$ was tested from $\mathrm{pH} 2-11$ for neat HAP, neat MMT, HAP-MMT nanocomposite and also for the mixture of neat HAP and neat MMT in the same ratio as in the HAP-MMT composite by keeping all the other parameters constant. According to the results illustrated in Fig. 4, HAP-MMT nanocomposite shows the highest adsorption percentage of $71 \%$ at $\mathrm{pH}$ 5. However, externally mixed HAP/MMT which was prepared by mixing HAP

Table 3 Thermodynamic parameters of fluoride adsorption for HAP and HAP-MMT

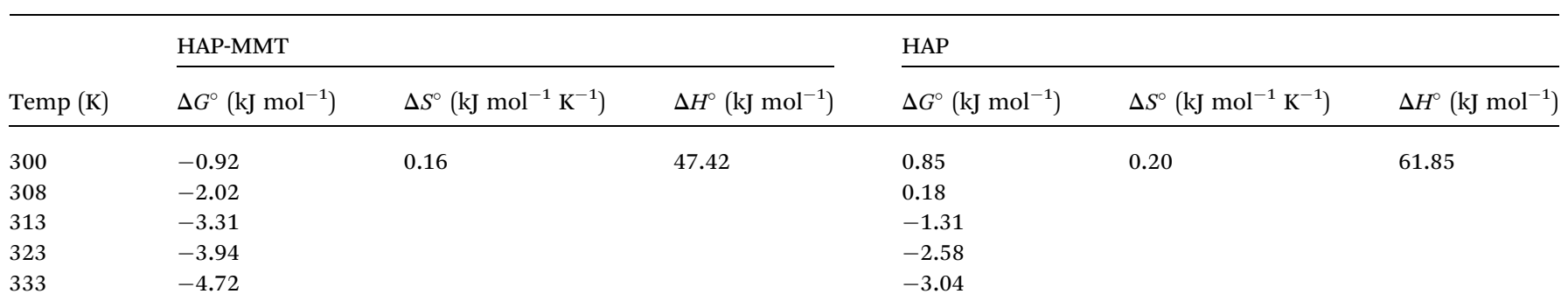




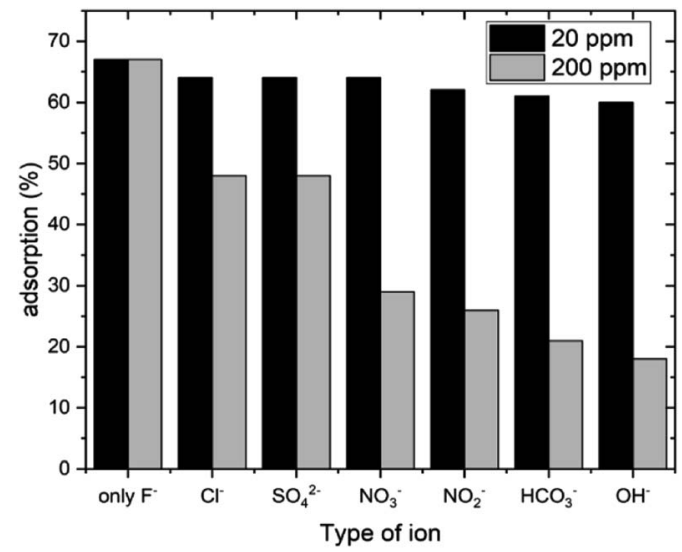

Fig. 5 Fluoride adsorption capacity in the presence of other ions for 60 minutes.

and MMT in to the same ratio of HAP-MMT showed a lower adsorption capacity.

This indeed indicated the need of exfoliated MMT structure with more adsorption sites for the adsorption of fluoride ions. MMT shows very poor fluoride adsorption and the highest adsorption capacity (40\%) was observed at $\mathrm{pH} 2$ where no adsorption could be observed at $\mathrm{pH}$ of normal drinking water or higher. Also, neat HAP showed a lower adsorption capacity compared to HAP-MMT at all the tested $\mathrm{pH}$ values. From these studies it is clear that only HAP-MMT system is suitable for drinking water purification.

\subsection{The effect of temperature and thermodynamics}

Thermodynamic parameters of an adsorption process can be used to determine its feasibility. Results obtained for the adsorption studies at different temperatures show that the adsorption capacities of both HAP and HAP-MMT are increased when the temperature is increased from $27{ }^{\circ} \mathrm{C}-60{ }^{\circ} \mathrm{C}$ indicating the endothermic nature of the process of adsorption. The results were used to calculate the thermodynamic parameters and the values obtained for $\Delta G^{\circ}, \Delta S^{\circ}$ and $\Delta H^{\circ}$ are tabulated in Table 3. The graph of $\ln K_{\mathrm{d}} v s$. $1 / \mathrm{T}$ which was used for the calculations of thermodynamic parameters for HAP-MMT and fluoride is given in Fig. S6 in ESI. $\dagger$ According to the $\Delta G^{\circ}$ values, fluoride adsorption by HAP-MMT is characteristic with a more favourable adsorption of fluoride. Positive $\Delta H^{\circ}$ value indicates that the adsorption process is endothermic. These observations agree with literature, as similar results have been reported for different adsorbents under varying experimental conditions..$^{39,55,56}$

\subsection{Effect of other ions}

The uptake of fluoride can be affected by other common ions present in water as they can act as competitive ions in the process of fluoride adsorption. Therefore, the adsorption of fluoride ions by HAP-MMT was investigated using other ions $\left(\mathrm{NO}_{3}{ }^{-}, \mathrm{NO}_{2}{ }^{-}, \mathrm{SO}_{4}{ }^{2-}, \mathrm{HCO}_{3}{ }^{-}, \mathrm{Cl}^{-}\right.$and $\left.\mathrm{OH}^{-}\right)$that may present in ground water. Two ion concentrations (20 ppm and $200 \mathrm{ppm}$ ) were used to investigate this. Results of the experiment are given in Fig. 5. It can be seen that there is a significant reduction in fluoride adsorption when the interfering ions are present at high concentrations. The highest interference was observed for $\mathrm{OH}^{-}$ions at both the tested concentrations. Interfering strength of the ions is in the order $\mathrm{OH}^{-}>\mathrm{HCO}_{3}{ }^{-}>\mathrm{NO}_{2}{ }^{-}>\mathrm{NO}_{3}{ }^{-}>\mathrm{SO}_{4}{ }^{2-}$ $>\mathrm{Cl}^{-}$.

\subsection{Reusability}

In order to test the reusability of HAP-MMT, a sample of HAPMMT was subjected to repeated fluoride adsorption. The material was regenerated as explained in the experimental section, prior to be used for fluoride adsorption. It was observed that the adsorption capacity was slightly decreased after each

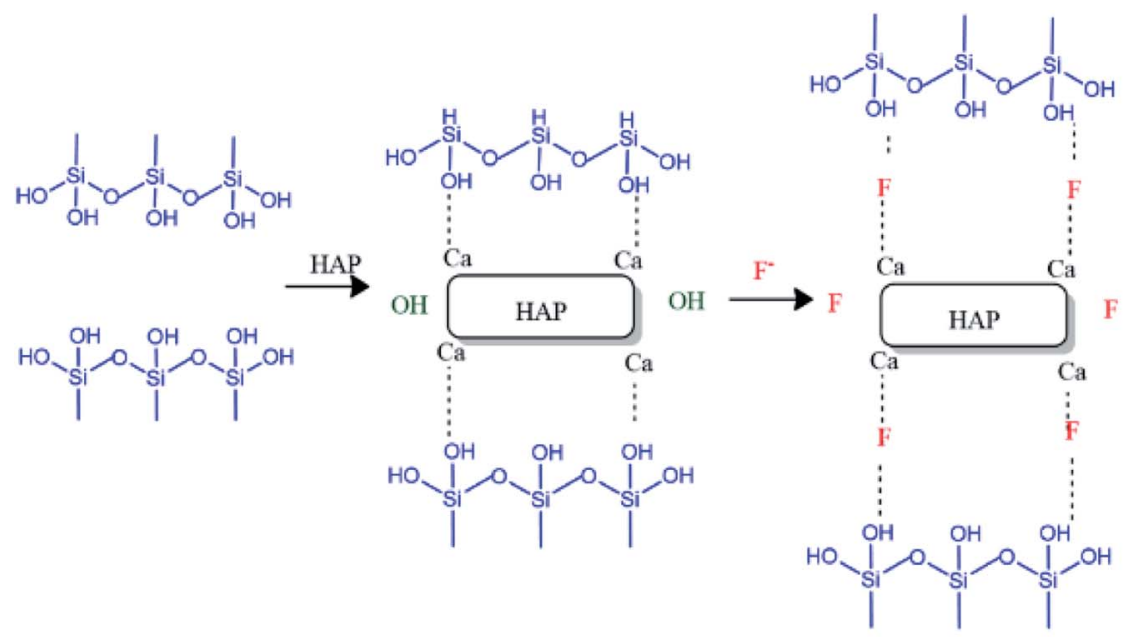

Fig. 6 Suggested mechanism explaining improved fluoride adsorption by HAP-MMT composite. 


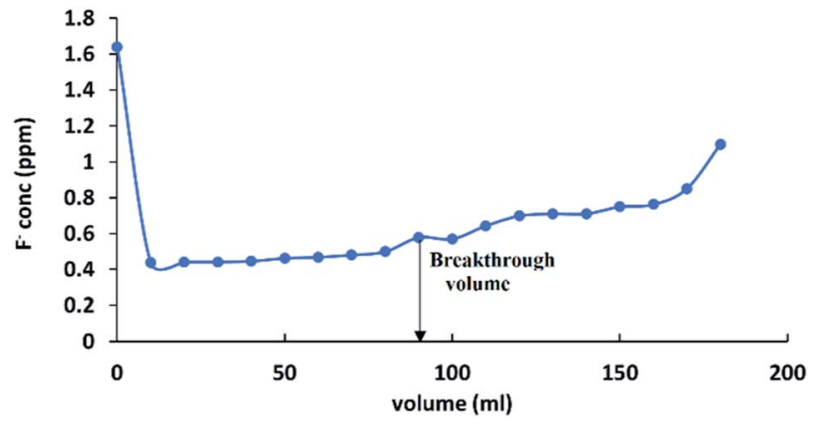

Fig. 7 Breakthrough curve for fluoride adsorption on to HAP-MMT.

regeneration cycle as the resulted percentage of fluoride adsorption changed from, $55 \%, 43 \%$ and $37 \%$ in three consecutive regeneration cycles. This shows that a complete desorption of fluorides ions has not taken place during regeneration.

\subsection{Mechanism of adsorption}

Fluoride adsorption by HAP has been proposed to occur via two pathways, namely by ion exchange with lattice $\mathrm{OH}^{-}$and by interaction with cationic centres. ${ }^{39,55,56}$ In the present work, we have observed an improved fluoride adsorption when HAP is interacting with MMT. In addition to the increment in surface area, the arrangement of adsorption sites may have played a role in improving the fluoride adsorption capacity. The very low uptake of fluoride by MMT at $\mathrm{pH}$ 5.5-7.0 range and the significant improvement of fluoride uptake by HAPMMT composite support this argument. The synergistic effect on fluoride adsorption is clearly evident as the in situ synthesized HAP-MMT material has a significantly high fluoride adsorption capacity compared to the physical mixture of HAP and MMT having the same molar ratio. Based on the structural data, morphological analysis and surface area measurements, mechanism involved in the adsorption of $\mathrm{F}^{-}$ions onto HAP-MMT composite could be suggested to follow the mechanism in Fig. 6. Accordingly, the possible initial step could be the immobilization of $\mathrm{Ca}^{2+}$ ions within the layers of MMT by anchoring onto hydroxyl groups. This may attract the phosphate ions resulting the formation of HAP on both internal and external surfaces. This can be attributed to the expansion of MMT layer as observed in XRD data (Fig. 1) and SEM data (Fig. S3(c)†). Due to this expansion, more $\mathrm{OH}^{-}$groups may now be available for $\mathrm{F}^{-}$ions to exchange with. In addition, the involvement of $\mathrm{Ca}^{2+}$ in anchoring $\mathrm{F}^{-}$with MMT may also play a role in improving the fluoride adsorption capacity.

\subsection{Breakthrough capacity calculated by gravity filtration}

Gravity filtration studies were carried out to identify the feasibility of using HAP-MMT nanocomposite in field applications. According to a recent study, the average fluoride concentration of the CKDu affected areas in Sri Lanka has been identified to be in the range of 1.5-0.5 $\mathrm{ppm}^{59-62}$ while non CKDu areas were reported with fluoride concentration below $0.5 \mathrm{ppm}$. In addition, dental fluorosis has also been reported with low concentration ranges and many studies indicate $0.5 \mathrm{ppm}$ of fluoride as the desirable level in drinking water. Therefore, in this work, gravity filtration studies were conducted using $1.5 \mathrm{ppm}$ of fluoride solution as the initial concentration and $0.5 \mathrm{ppm}$ was considered as the safe limit, for fluorides. The break through capacity was calculated using the volume that could reduce the concentration of $1.5 \mathrm{ppm}$ fluoride solution up to $0.5 \mathrm{ppm}$, when it is passed through a column with $1 \mathrm{~cm}$ diameter at a flow rate of $0.33 \mathrm{ml} \mathrm{s}^{-1}$. The breakthrough curve is represented in Fig. 7 and the break through volume for $0.05 \mathrm{~g}$ was found as $80 \mathrm{ml}$ as show in the graph. Therefore, it can be calculated as $1600 \mathrm{ml} \mathrm{g}^{-1}$ for a unit mass. According to the literature, many adsorbents are not capable of adsorbing fluoride at concentrations below $2 \mathrm{ppm}$ in the $\mathrm{pH}$ range of drinking water $\mathrm{pH}(5.5-7) .^{32}$

Table 4 Comparison of fluoride adsorption properties of HAP-MMT nanocomposite with other reported HAP based materials

\begin{tabular}{|c|c|c|c|c|c|c|c|c|}
\hline \multirow[b]{2}{*}{ Adsorbent (mm) } & \multirow[b]{2}{*}{$\begin{array}{l}\text { Concentration range } \\
\text { or highest concentration } \\
\text { used (ppm) }\end{array}$} & \multirow[b]{2}{*}{$\begin{array}{l}\text { Contact } \\
\text { Time } \\
(\mathrm{min})\end{array}$} & \multirow[b]{2}{*}{$\begin{array}{l}\text { Adsorption } \\
\text { capacity } \\
\left(\mathrm{mg} \mathrm{g}^{-1}\right)\end{array}$} & \multicolumn{4}{|c|}{ Filter bed column studies } & \multirow[b]{2}{*}{ Ref. } \\
\hline & & & & $\begin{array}{l}\text { Initial } \\
\text { concentration }\end{array}$ & Flow rate & $\begin{array}{l}\text { Diameter, } \\
\text { thickness } \\
\text { of column }\end{array}$ & $\begin{array}{l}\text { Break } \\
\text { through } \\
\text { capacity }\end{array}$ & \\
\hline $\begin{array}{l}\text { Modified HAP with activated } \\
\text { alumina }\end{array}$ & $10-200$ & 480 & 14.4 & 3 & Not given & 11 & $400 \mathrm{~L} \mathrm{~g}^{-1}$ & 63 \\
\hline Al-HAP & 200 & 180 & 98.8 & 5 & $\begin{array}{l}10 \\
\mathrm{ml} \mathrm{min}\end{array}$ & $2,0.3$ & $\begin{array}{l}1568 \mathrm{~L} \\
\mathrm{~m}^{-2}\end{array}$ & 64 \\
\hline HAP-MMT & 30 & 30 & 16.7 & 1.5 & $\begin{array}{l}10 \\
\mathrm{ml} \mathrm{min}\end{array}$ & $10,0.2$ & $1600 \mathrm{~L} \mathrm{~g}^{-1}$ & $\begin{array}{l}\text { This } \\
\text { work }\end{array}$ \\
\hline HAP-alginate & 10 & 30 & 3.87 & Not reported & & & & 57 \\
\hline HAP-cellulose & 10 & 360 & 4.2 & Not reported & & & & 35 \\
\hline Magnetic HAP-alginate & 10 & 30 & 4.05 & Not reported & & & & 15 \\
\hline HAP-CTS & 10 & 30 & 1.56 & Not reported & & & & 65 \\
\hline Multiwall CNT-HAP & $3-50$ & 150 & 30.22 & Not reported & & & & 30 \\
\hline HAP-gelatin & $8-14$ & & 4.157 & Not reported & & & & 58 \\
\hline CNT-HAP & - & 300 & 11.05 & Not reported & & & & 58 \\
\hline Mineral substituted HAP & 10 & 60 & 8.36 & Not reported & & & & 66 \\
\hline
\end{tabular}


In addition, Table 4 was used to compare the adsorption properties resulted from batch adsorption studies and gravity filtration studies of some of the reported HAP based nanocomposites prepared using nontoxic bulk materials such as biopolymers. According to that the HAP-MMT nanocomposite of this work show a considerably good adsorption capacity and a short contact time. To the best of our knowledge, gravity filtration studies reported in literature have been conducted considering $1.5 \mathrm{ppm}$ as the safe limit. However, in the present study, we have demonstrated that the HAP-MMT nanocomposite can be used to lower the fluoride concentration down to $0.5 \mathrm{ppm}$.

\section{Conclusion}

A novel material for fluoride adsorption has been synthesized by incorporating hydroxyapatite (HAP) in to montmorillonite (MMT). The resultant material has a high fluoride adsorption capacity in the $\mathrm{pH}$ range of drinking water compared to a physical mixture of HAP and MMT. The improvement in fluoride adsorption is suggested to be the expansion of layers of MMT and incorporation of HAP in to the layers. The fluoride adsorption capacities of MMT, HAP and HAP-MMT were 2.44, 6.7 and $16.7 \mathrm{mg} \mathrm{g}^{-1}$ respectively. Also, the gravity filtration studies indicated that the HAP-MMT is a promising material which can be applied in real applications.

\section{Conflicts of interest}

There are no conflicts of interest to declare.

\section{Acknowledgements}

Authors like to express their sincere gratitude to National Research Council (NRC) of Sri Lanka for the financial support provided through a Target Oriented (TO) multidisciplinary research grant, NRC TO $16-18$. The authors are also grateful to the Sri Lanka Institute of Nanotechnology, and the technical officers at the Department of Chemistry, University of Colombo for the necessary support provided.

\section{References}

1 D. Kanduti, P. Sterbenk and B. Artnik, Fluoride: A Review of Use and Effects on Health, Mater. Soc. Med., 2016, 28(2), 133, available from: http://www.scopemed.org/fulltextpdf.php? $\mathrm{mno}=223171$.

2 World Health Organization, Guidelines for Drinking-water Quality Fourth Edition WHO Library Cataloguing, in Publication Data Guidelines for drinking-water quality, 4th edn, 2017, available from: http://www.who.int.

3 S. L. Choubisa, L. Choubisa and D. K. Choubisa, Endemic Fluorosis in Rajasthan, Indian J. Environ. Health, 2001, 43(4), 177-189.

4 D. Browne, H. Whelton and D. O'Mullane, Fluoride metabolism and fluorosis, J. Dent., 2005, 33(3), 177-186.
5 K. Babaeivelni and A. P. Khodadoust, Adsorption of fluoride onto crystalline titanium dioxide: Effect of $\mathrm{pH}$, ionic strength, and co-existing ions, J. Colloid Interface Sci., 2013, 394(1), 419-427, DOI: 10.1016/j.jcis.2012.11.063.

6 R. W. Dharmaratne, Fluoride in drinking water and diet: the causative factor of chronic kidney diseases in the North Central Province of Sri Lanka, Environ. Health Prev. Med., 2015, 20(4), 237-242.

7 M. Shanika Fernando, R. M. De Silva and K. M. Nalin De Silva, Synthesis, characterization, and application of nano hydroxyapatite and nanocomposite of hydroxyapatite with granular activated carbon for the removal of $\mathrm{Pb}^{2+}$ from aqueous solutions, Appl. Surf. Sci., 2015, 351, 95-103.

8 H. Aissam, F. Errachidi, M. J. Penninckx, M. Merzouki and M. Benlemlih, Production of tannase by Aspergillus niger HA37 growing on tannic acid and Olive Mill Waste Waters, J. Microbiol. Biotechnol., 2005, 609-614.

9 D. Zhang, H. Luo, L. Zheng, K. Wang, H. Li, Y. Wang, et al. Utilization of waste phosphogypsum to prepare hydroxyapatite nanoparticles and its application towards removal of fluoride from aqueous solution, J. Hazard. Mater., 2012, 241-242, 418-426, available from: https:// www.sciencedirect.com/science/article/pii/ S0304389412009995.

10 A. Teimouri, S. Ghanavati Nasab, S. Habibollahi, M. FazelNajafabadi and A. N. Chermahini, Synthesis and characterization of a chitosan/montmorillonite/ZrO 2 nanocomposite and its application as an adsorbent for removal of fluoride, $R S C A d v$., 2015, 5(9), 6771-6781, DOI: 10.1039/C4RA13139H.

11 Short Communication Pyrolysis of Coconut Shell and its Potential as Fuel, Agric. Wastes. 1986, 17, 313-317.

12 M. Yesilbas, M. Holmboe and J. F. Boily, Cohesive vibrational and structural depiction of intercalated water in montmorillonite, ACS Earth Space Chem., 2018, 2(1), 3847.

13 L. Wang, Y. Xie, J. Yang, X. Zhu and Q. Hu, RSC Advances Insight into mechanisms of fluoride removal from contaminated groundwater using lanthanum- modified bone waste, RSC Adv., 2017, 54291-54305.

14 Z. Zhou, Y. Yu, Z. Ding, M. Zuo and C. Jing, Competitive adsorption of arsenic and fluoride on $\{201\} \mathrm{TiO}_{2}$, Appl. Surf. Sci., 2019, 466, 425-432.

15 Y. Zhang, X. Lin, Q. Zhou and X. Luo, Fluoride adsorption from aqueous solution by magnetic core-shell $\mathrm{Fe}_{3} \mathrm{O}_{4} @$ alginate-La particles fabricated via electrocoextrusion, J. Hazard. Mater., 2016, 389, 34-45, DOI: 10.1016/j.apsusc.2016.07.087.

16 Y. Huang, Y. Shih and C. Chang, Adsorption of fluoride by waste iron oxide: the effects of solution $\mathrm{pH}$, major coexisting anions, and adsorbent calcination temperature, J. Hazard. Mater., 2011, 186(2-3), 1355-1359, DOI: 10.1016/ j.jhazmat.2010.12.025.

17 P. Mondal and S. George, A review on adsorbents used for defluoridation of drinking water, Rev. Environ. Sci. Biotechnol., 2015, 14(2), 195-210. 
18 Y. H. Li, S. Wang, A. Cao, D. Zhao, X. Zhang, C. Xu, et al. Adsorption of fluoride from water by amorphous alumina supported on carbon nanotubes, Chem. Phys. Lett., 2001, 350(5-6), 412-416.

19 A. Ghosh, S. Chakrabarti, K. Biswas and U. C. Ghosh, Agglomerated nanoparticles of hydrous Ce(IV) $+\mathrm{Zr}(\mathrm{IV})$ mixed oxide: Preparation, characterization and physicochemical aspects on fluoride adsorption, J. Hazard. Mater. 2014, 307, 665-676, DOI: 10.1016/ j.apsusc.2014.04.095.

20 S. P. Suriyaraj and R. Selvakumar, Advances in nanomaterial based approaches for enhanced fluoride and nitrate removal from contaminated water, RSC Adv., 2016, 6(13), 1056510583, DOI: 10.1039/C5RA24789F.

21 C. Xu, J. Li, F. He, Y. Cui, C. Huang, H. Jin, et al. $\mathrm{Al}_{2} \mathrm{O}_{3}-\mathrm{Fe}_{3} \mathrm{O}_{4^{-}}$ expanded graphite nano-sandwich structure for fluoride removal from aqueous solution, $R S C A d v$., 2016, 6(99), 97376-97384.

22 V. A. Online, L. Chen, J. He, X. Cai and J. Liu, Performance and mechanism of hierarchically porous $\mathrm{Ce}-\mathrm{Zr}$ oxide 2 nanospheres encapsulated calcium alginate beads for fluoride removal from water, RSC Adv., 2016.

23 S. Raghav and D. Kumar, Adsorption Equilibrium, Kinetics, and Thermodynamic Studies of Fluoride Adsorbed by Tetrametallic Oxide Adsorbent, J. Chem. Eng. Data, 2018, 63(5), 1682-1697, DOI: 10.1021/acs.jced.8b00024.

24 C. Zhang, Y. Li, T. Wang, Y. Jiang and H. Wang, Applied Surface Science Adsorption of drinking water fluoride on a micron-sized magnetic $\mathrm{Fe}_{3} \mathrm{O}_{4}$ @ Fe-Ti composite adsorbent, J. Hazard. Mater., 2016, 363, 507-515, DOI: 10.1016/j.apsusc.2015.12.071.

25 J. Wang, W. Xu, L. Chen, Y. Jia, L. Wang, X. Huang, et al. Excellent fluoride removal performance by $\mathrm{CeO}_{2}-\mathrm{ZrO}_{2}$ nanocages in water environment, Chem. Eng. J., 2013, 231, 198-205.

26 S. Deng, H. Liu, W. Zhou, J. Huang and G. Yu, Mn - Ce oxide as a high-capacity adsorbent for fluoride removal from water, J. Hazard. Mater., 2011, 186(2-3), 1360-1366, DOI: 10.1016/j.jhazmat.2010.12.024.

27 L. Chen, B. He, S. He, T. Wang, C. Su and Y. Jin, Fe-Ti oxide nano-adsorbent synthesized by co-precipitation for fluoride removal from drinking water and its adsorption mechanism, Powder Technol., 2012, 227, 3-8, DOI: 10.1016/ j.powtec.2011.11.030.

$28 \mathrm{~T}$. Wu, L. Mao and H. Wang, Adsorption of fluoride on $\mathrm{Mg} / \mathrm{Fe}$ layered double hydroxides material prepared via hydrothermal process, RSC Adv., 2015, 5(30), 23246-23254, DOI: 10.1039/C4RA16839A.

29 C. Binns, Introduction to Nanoscience and Nanotechnology, 2010.

30 Z. Y. Ruan, Y. X. Tian, J. F. Ruan, G. J. Cui, K. W. Iqbal, A. Iqbal, et al. Synthesis of hydroxyapatite/multi-walled carbon nanotubes for the removal of fluoride ions from solution, J. Hazard. Mater., 2017, 412, 578-590, DOI: 10.1016/j.apsusc.2017.03.215.

31 Q. Tang, T. Duan, P. Li, P. Zhang and D. Wu, Enhanced Defluoridation Capacity From Aqueous Media via
Hydroxyapatite Decorated With Carbon Nanotube, Front. Chem., 2018, 6.

32 M. Habuda-Stanić, M. Ravančić and A. Flanagan, A Review on Adsorption of Fluoride from Aqueous Solution, Materials, 2014, 7(9), 6317-6366, available from: http:// www.mdpi.com/1996-1944/7/9/6317/.

33 D. C. Manatunga, R. M. de Silva, K. M. N. de Silva and R. Ratnaweera, Natural polysaccharides leading to super adsorbent hydroxyapatite nanoparticles for the removal of heavy metals and dyes from aqueous solutions, RSC Adv., 2016, 6(107), 105618-105630.

34 H. Zhang, X. Shi, A. Tian, L. Wang and C. Liu, Electrochemical properties of $\mathrm{Ti}^{3+}$ doped $\mathrm{Ag}$-Ti nanotube arrays coated with hydroxyapatite, J. Hazard. Mater., 2018, 436, 579-584, DOI: 10.1016/j.apsusc.2017.12.048.

35 X. Yu, S. Tong, M. Ge and J. Zuo, Removal of fluoride from drinking water by cellulose@hydroxyapatite nanocomposites, Carbohydr. Polym., 2013, 92(1), 269-275, DOI: 10.1016/j.carbpol.2012.09.045.

36 V. Sternitzke, R. Kaegi, J.-N. Audinot, E. Lewin, J. G. Hering and C. A. Johnson, Uptake of Fluoride from Aqueous Solution on Nano-Sized Hydroxyapatite: Examination of a Fluoridated Surface Layer, Environ. Sci. Technol., 2012 Jan 17, 46(2), 802-809, DOI: 10.1021/es202750t.

37 G. E. J. Poinern, M. K. Ghosh, Y. J. Ng, T. B. Issa, S. Anand and P. Singh, Defluoridation behavior of nanostructured hydroxyapatite synthesized through an ultrasonic and microwave combined technique, J. Hazard. Mater., 2011, 185(1), 29-37.

38 V. Sternitzke and C. A. Johnson, Adsorption of fluoride on synthetic hydroxyapatite, Geochim. Cosmochim. Acta, 2009, 73(13), A1273.

39 S. Gao, J. Cui and Z. Wei, Study on the fluoride adsorption of various apatite materials in aqueous solution, J. Fluorine Chem., 2009, 130, 1035-1041.

40 B. Bar Yosef, I. Afik and R. Rosenberg, Fluoride sorption by montmorillonite and kaolinite, Soil Sci., 1988, 145(3), 195200.

41 G. Karthikeyan and A. Pius GA, Fluoride adsorption studies of montmorillonite clay, Indian J. Chem. Technol., 2005, 12, 263-272.

42 A. Tor, Removal of fluoride from an aqueous solution by using montmorillonite, Desalination, 2006, 201(1-3), 267276, available from: https://www.sciencedirect.com/science/ article/pii/S0011916406011714.

43 S. P. Kamble, P. Dixit, S. S. Rayalu and N. K. Labhsetwar, Defluoridation of drinking water using chemically modified bentonite clay, Desalination, 2009, 249(2), 687-693.

44 J. H. Kim, C. G. Lee, J. A. Park, J. K. Kang, N. C. Choi and S. B. Kim, Use of pyrophyllite clay for fluoride removal from aqueous solution, Desalin. Water Treat., 2013, 51(1618), 3408-3416.

45 Q. Guo and E. J. Reardon, Fluoride removal from water by meixnerite and its calcination product, Appl. Clay Sci., 2012, 56, 7-15, DOI: 10.1016/j.clay.2011.11.013.

46 A. Vinati, B. Mahanty and S. K. Behera, Clay and clay minerals for fluoride removal from water: A state-of-the-art 
review, Appl. Clay Sci., 2015, 114, 340-348, DOI: 10.1016/ j.clay.2015.06.013.

47 D. Qin, X. Niu, M. Qiao, G. Liu, H. Li and Z. Meng, Adsorption of ferrous ions onto montmorillonites, $J$. Hazard. Mater., 2015, 333, 170-177, DOI: 10.1016/ j.apsusc.2015.02.019.

48 Campinas-unicamp UE De, C. D. R. Minerais and Matogrosso-ufmt UF De. Performance of modified montmorillonite clay in mercury adsorption process and thermodynamic studies. 2008, 11, 20-23.

49 V. Bolis, C. Morterra, B. Fubini, P. Ugliengo and E. Garrone, Temkin-Type Model for the Description of Induced Heterogeneity: CO Adsorption on Group 4 Transition Metal Dioxides, Langmuir, 1993, 9(6), 1521-1528.

50 O. Rahmanian, M. Dinari and M. K. Abdolmaleki, Carbon quantum dots/layered double hydroxide hybrid for fast and efficient decontamination of $\mathrm{Cd}(\mathrm{II})$ : The adsorption kinetics and isotherms, J. Hazard. Mater., 2018, 428, 272279, DOI: 10.1016/j.apsusc.2017.09.152.

51 P. Saha and S. Chowdhury, Thermodynamics, ed. M. Tadashi, InTech, 2011, pp. 350-360.

52 F. Lin, G. Zhu, Y. Shen, Z. Zhang and B. Dong, Study on the modified montmorillonite for adsorbing formaldehyde, $J$. Hazard. Mater., 2015, 356, 150-156, DOI: 10.1016/ j.apsusc.2015.07.186.

53 M. B. Ahmad, K. Shameli, W. Zin and W. Yunus, Synthesis and Characterization of Silver/Clay/Starch Bionanocomposites by Green Method, Adv. Mater., 2010, 4(7), 2158-2165.

54 G. M. Poralan, J. E. Gambe, E. M. Alcantara and R. M. Vequizo, X-ray diffraction and infrared spectroscopy analyses on the crystallinity of engineered biological hydroxyapatite for medical application, IOP Conf. Ser.: Mater. Sci. Eng., 2015, 79(1).

55 B. Nayak, A. Samant, R. Patel and P. K. Misra, Comprehensive Understanding of the Kinetics and Mechanism of Fluoride Removal over a Potent Nanocrystalline Hydroxyapatite Surface, ACS Omega, 2017, 8118-8128.

56 N. Madusanka, K. M. N. De Silva and G. Amaratunga, Curcumine activated carboxymethyl cellulosemontmorillonite clay nanocomposite having enhanced curcumine release in aqueous media, Carbohydr. Polym., 2015, 134, 695-699, DOI: 10.1016/j.carbpol.2015.08.030.

57 K. Pandi and N. Viswanathan, Synthesis of alginate bioencapsulated nano-hydroxyapatite composite for selective fluoride sorption, Carbohydr. Polym., 2014, 112, 662-667, DOI: 10.1016/j.carbpol.2014.06.029.

$58 \mathrm{~K}$. Pandi and N. Viswanathan, In situ precipitation of nanohydroxyapatite in gelatin polymatrix towards specific fluoride sorption, Int. J. Biol. Macromol., 2015, 74, 351-359, DOI: 10.1016/j.ijbiomac.2014.12.004.

59 R. Chandrajith, J. P. Padmasiri, C. B. Dissanayake and K. M. Prematilaka, Spatial distribution of fluoride in groundwater of Sri Lanka, J. Natl. Sci. Found. Sri Lanka, 2012, 40(4), 303-309.

60 K. E. Levine, J. H. Redmon, M. F. Elledge, K. P. Wanigasuriya, K. Smith, B. Munoz, et al. Quest to identify geochemical risk factors associated with chronic kidney disease of unknown etiology (CKDu) in an endemic region of Sri Lankaa multimedia laboratory analysis of biological, food, and environmental samples, Environ. Monit. Assess., 2016, 188(10), 548, DOI: 10.1007/s10661-016-5524-8.

61 C. B. Dissanayake and R. Chandrajith, Groundwater fluoride as a geochemical marker in the etiology of chronic kidney disease of unknown origin in Sri Lanka, Ceylon J. Sci., Biol. Sci., 2017, 46(2), 3, DOI: 10.4038/cjs.v46i2.7425/.

62 S. Wickramarathna, S. Balasooriya, S. Diyabalanage and R. Chandrajith, Tracing environmental aetiological factors of chronic kidney diseases in the dry zone of Sri Lanka-A hydrogeochemical and isotope approach, J. Trace Elem. Med. Biol., 2017, 44, 298-306, DOI: 10.1016/ j.jtemb.2017.08.013.

63 G. Tomar, A. Thareja and S. Sarkar, Enhanced fluoride removal by hydroxyapatite-modified activated alumina, Int. J. Environ. Sci. Technol., 2015, 12(9), 2809-2818, DOI: 10.1007/s13762-014-0653-5.

64 J. He, K. Chen, X. Cai, Y. Li, C. Wang, K. Zhang, et al. A biocompatible and novelly-defined Al-HAP adsorption membrane for highly effective removal of fluoride from drinking water, J. Colloid Interface Sci., 2017, 490, 97-107, DOI: 10.1016/j.jcis.2016.11.009.

65 C. Sairam Sundaram, N. Viswanathan and S. Meenakshi, Uptake of fluoride by nano-hydroxyapatite/chitosan, a bioinorganic composite, Bioresour. Technol., 2008, 99(17), 8226-8230.

66 A. Nagaraj, M. A. Munusamy, M. Ahmed, S. Suresh Kumar and M. Rajan, Hydrothermal synthesis of a mineralsubstituted hydroxyapatite nanocomposite material for fluoride removal from drinking water, New J. Chem., 2018, 42(15), 12711-12721. 